\title{
Comparative Study on Fractional Isothermal Chemical Model
}

Khaled Mohammed SAAD ${ }^{1}$ and Khaled M Saad ${ }^{2,3}$

${ }^{1}$ Affiliation not available

${ }^{2}$ Department of Mathematics, College of Arts and Sciences, Kingdom of Saudi Arabia, Najran University

${ }^{3}$ Department of Mathematics, Faculty of Applied Science, Taiz University

November 30, 2020

\section{Hosted file}

KhaledSAAD.pdf available at https://authorea.com/users/377697/articles/495847-comparativestudy-on-fractional-isothermal-chemical-model 